J. Dairy Sci. 97:7505-7514

http://dx.doi.org/10.3168/jds.2014-8090

(c) American Dairy Science Association ${ }^{\circledR}, 2014$.

\title{
Implementing electronic identification for performance recording in sheep: I. Manual versus semiautomatic and automatic recording systems in dairy and meat farms
}

\author{
A. Ait-Saidi, ${ }^{*}$ G. Caja, ${ }^{* 1}$ A. A. K. Salama, ${ }^{*} \dagger$ and S. Carné ${ }^{* 2}$ \\ *Group of Research in Ruminants (G2R), Department of Animal and Food Sciences, Universitat Autònoma de Barcelona, 08193 Bellaterra, Spain \\ †Sheep and Goat Research Department, Animal Production Research Institute, 12311 Dokki, Giza, Egypt
}

\begin{abstract}
With the aim of assessing the secondary benefits of using electronic identification (e-ID) in sheep farms, we compared the use of manual (M), semiautomatic (SA), and automatic (AU) data-collection systems for performance recording (i.e., milk, lambing, and weight) in 3 experiments. Ewes were identified with visual ear tags and electronic rumen boluses. The M system consisted of visual ear tags, on-paper data recording, and manual data uploading to a computer; the use of a personal digital assistant (PDA) for data recording and data uploading was also done in M. The SA system used a handheld reader (HHR) for e-ID, data recording, and uploading. Both PDA and HHR used Bluetooth for uploading. The AU system was only used for body weight recording and consisted of e-ID, data recording in an electronic scale, and data uploading. In experiment 1 , $\mathrm{M}$ and SA milk-recording systems were compared in a flock of 48 dairy ewes. Ewes were milked once- $(\times 1, \mathrm{n}$ $=24)$ or twice- $(\times 2, \mathrm{n}=24)$ daily in a $2 \times 12$ milking parlor and processed in groups of 24 . Milk yield (1.21 $\pm 0.04 \mathrm{~L} / \mathrm{d}$, on average) was $36 \%$ lower in $\times 1$ than $\times 2$ ewes and milk recording time correlated positively with milk yield $\left(\mathrm{R}^{2}=0.71\right)$. Data transfer was markedly faster for PDA and HHR than for M. As a result, overall milk recording time was faster in SA $(\times 1=12.1 \pm$ $0.6 \mathrm{~min} / 24$ ewes; $\times 2=22.1 \pm 0.9 \mathrm{~min} / 24$ ewes) than $\mathrm{M}$ $(\times 1=14.9 \pm 0.6 \mathrm{~min} / 24$ ewes; $\times 2=27.9 \pm 1.0 \mathrm{~min} / 24$ ewes). No differences between PDA and HHR were detected. Time savings, with regard to $\mathrm{M}$, were greater for $\times 2$ than for $\times 1(5.6 \pm 0.2$ vs. $2.8 \pm 0.1$ min per 24 ewes, respectively), but similar for PDA and HHR. Data transfer errors averaged $3.6 \%$ in $\mathrm{M}$, whereas no errors were found in either SA system. In experiment 2, 73 dairy and 80 meat ewes were monitored at lambing
\end{abstract}

Received February 28, 2014.

Accepted August 27, 2104.

${ }^{1}$ Corresponding author: gerardo.caja@uab.es

${ }^{2}$ Current address: Industrial Técnica Pecuaria (Itpsa), Av. de Roma 157, 08011 Barcelona, Spain. using $\mathrm{M}$ and SA. Overall time for lambing recording was greater in $\mathrm{M}$ than SA in dairy $(1.67 \pm 0.06$ vs. $0.87 \pm 0.04 \mathrm{~min} /$ ewe) and meat ( $1.30 \pm 0.03$ vs. $0.73 \pm$ $0.03 \mathrm{~min} / \mathrm{ewe}$ ) ewes. Recording errors were greater in dairy $(9.6 \%)$ than in meat $(1.9 \%)$ ewes. Data uploading errors only occurred in M (4.9\%). In experiment 3, 120 dairy and 120 meat ewes were weighed using $\mathrm{M}$ and AU systems. In both flocks, mean BW recording and data uploading times, as well as overall BW recording time $(0.63 \pm 0.02$ and $0.25 \pm 0.01 \mathrm{~min} / \mathrm{ewe}$, respectively) were greater in $\mathrm{M}$ than in $\mathrm{AU}$, and uploading errors only occurred in M (8.8\%). In conclusion, HHR and PDA systems were time-effective for performance recording, both saving time and improving data accuracy. Working load and time for ewe identification were faster in HHR but it did not affect the performance recording time. The PDA was the fastest device for data download. Further research will evaluate the costs of implementing e-ID for performance recording and other uses in sheep farms.

Key words: ear tag, electronic identification, milk recording, rumen bolus, transponder

\section{INTRODUCTION}

Animal identification systems have evolved with technology, and different systems for the livestock industry are currently available and economically affordable (Caja et al., 2004; Bass et al., 2008). Among them, visual (v-ID; e.g., plastic ear tags) and electronic (eID; e.g., injectable, ear tag and bolus transponders) identification systems are frequently used in practice.

Despite being mandatory in some countries for sheep and goats, the primary objectives of adopting a national animal identification system (i.e., food safety, animal-borne outbreaks, animal health surveillance, disease eradication, animal product traceability) are not well understood by the stakeholders because implementing an identification system increases their production costs. Costs of e-ID are related to the device performance and the size of operations, the acquisition 
values of the tagging and reading devices being of the foremost importance (Saa et al., 2005; Butler et al., 2009).

European Regulation CE 21/2004 (modified by CE 933/2008 and CE 759/2009; European Commision, 2004, 2008, 2009) made e-ID mandatory in European Union member states with sheep and goat populations greater than 600,000 head. Nevertheless, a reaction against the obligatory nature of this regulation has occurred based on the apparent lack of direct advantages for the stakeholders, which are currently supporting the cost of acquiring the e-ID devices (United Kingdom Parliament, 2008; Grassi, 2013).

Sheep farm efficiency is improved when adequate information is available for making decisions, which requires frequent data recording (e.g., flock inventory, performance recording). Permanent identification is a key for individual performance recording during the animal's productive life. Although acquisition of v-ID devices is always less expensive than e-ID, its use is burdened by labor and costs associated with reading, data recording, and data management, which are key steps in performance recording.

On-farm performance recording practices, such as milk recording, require considerable time and labor from the farmers and are scarcely widespread in the world dairy sheep industry $(<20 \%$; ICAR, 2014). Combining e-ID with automatic milk meters offered the possibility of reducing the associated cost of automatic milk-recording systems in dairy cows (Ordolff, 2001). Automatic milk meters for small dairy ruminants are also available (Ricard et al., 1994; ICAR, 2012) and are commercially offered in dairy sheep and goat milking parlors (Afimilk, 2014; DeLaval, 2014). Nevertheless, the use of e-ID and visual recording jars is a time- and cost-effective alternative to automatic milk-recording systems in dairy goat farms (Caja et al., 1999b; AitSaidi et al., 2008).

Sheep e-ID based on transponders included in ear tags (Caja et al., 1996; ADAS, 2006), injects (Marie et al., 1994; Caja et al., 1996, 1998; Conill et al., 2002), and rumen boluses (Caja et al., 1999a; Garín et al., 2003; Ghirardi et al., 2006) proved to be effective under on-field conditions. The choice of devices may depend on readability performances, species and breed, exploitation conditions, and additional on-farm uses, as is the case of performance recording. Current interest in livestock precision techniques highlighted the need for developing new tools to record welfare indicators and performances (Morris et al., 2012; Cappai et al., 2014). Innovative and robust handheld readers, with userfriendly program interfaces (San Miguel et al., 2005; Abas et al., 2007) and affordable purchasing costs, are also needed (Samad et al., 2010; Caja et al., 2014).
No information is available on the secondary benefits of using e-ID for dairy sheep farm management practices, including the monthly periodical milk recording test, which is a long, time-consuming, and costly duty (Milán et al., 2014). The objective of the current study was to evaluate the labor time and the data errors of performance recording in dairy and meat ewes when (1) a manual system (M) based on v-ET and manual data collection; (2) a semiautomatic (SA) systems based on v-ID and a personal digital assistant (PDA) for data recording, or e-ID and the use of a handheld reader (HHR) for data capturing and recording; and (3) an automatic system (AU) based on e-ID and an automatic data collection device were used.

\section{MATERIALS AND METHODS}

\section{Animals and Management Conditions}

Animal care conditions and management practices agreed with the procedures stated by the Ethical Committee of Animal and Human Experimentation of the Universitat Autònoma de Barcelona and the codes of recommendations for the welfare of livestock of the Ministry of Agriculture, Alimentation and Environment of Spain (MAPA, 2007). The experiments were done using the dairy $(\mathrm{n}=114$ ewes $)$ and meat $(\mathrm{n}=$ 102 ewes) flocks located at the experimental farm of the Servei de Granges i Camps Experimentals of the Universitat Autònoma de Barcelona in Bellaterra (Barcelona, Spain).

\section{Experiment 1: Milk-Recording Systems Comparison}

A total of 48 dairy ewes (Manchega, $n=26$; Lacaune, $\mathrm{n}=22$ ) were used. Ewes were divided into 2 balanced groups according to milking frequency: once daily $(\times \mathbf{1}$; $\mathrm{n}=24)$ and twice daily $(\times \mathbf{2} ; \mathrm{n}=24)$. Ewes were milked $(\times 1=0830 \mathrm{~h} ; \times 2=0800$ and $1730 \mathrm{~h})$ in a double 12-stall Casse system $(2 \times 12)$ parallel milking parlor (Westfalia-Surge Ibérica, Granollers, Barcelona, Spain) equipped with a low milk pipeline, 6 milking units on each side, recording jars, and head lockers. Usual machine milking settings for the breeds were used (vacuum $=42 \mathrm{kPa}$; pulsation rate $=120$ pulses $/$ min; pulsation ratio $=50 \%)$. Milking routine included machine milking (after cluster attachment without udder preparation), machine stripping, cluster removal, and disinfection by teat dipping (P3-ioshield, Ecolab Hispano-Portuguesa, Barcelona, Spain). Ewes grazed on an Italian ryegrass pasture for $6 \mathrm{~h} / \mathrm{d}$; they were supplemented with $0.5 \mathrm{~kg}$ of dehydrated tall fescue hay and $0.5 \mathrm{~kg} / \mathrm{d}$ of alfalfa pellets in the shelter, and with 0.5 to $1.0 \mathrm{~kg} / \mathrm{d}$ of a commercial concentrate $(1.89$ Mcal 
of $\mathrm{NE}_{\mathrm{L}} / \mathrm{kg} ; 18.8 \% \mathrm{CP}$, as fed) in the milking parlor, according to milk yield.

The experiment was carried out when the ewes were in midlactation (70-140 DIM) and consisted of 10 milk recording test days at weekly intervals by treatment. Experimental design was a factorial with 2 fixed daily milking frequencies $(\times 1$ and $\times 2)$ and 3 milk-recording systems applied at random (M, PDA, and HHR). Milk recording data $(\mathrm{n}=1,440)$ were collected in random groups of 12 ewes by milking frequency.

Manual Milk Recording. Ewes were visually identified on the right ear with an official visual ear tag (v-ET; polyurethane, 2 yellow flags; male flag $=40 \times$ $38 \mathrm{~mm}$; female flag $=42 \times 38 \mathrm{~mm}$; total weight $=5.2$ g; Azasa-Allflex, Madrid, Spain) which were laser recorded with 14 alphanumeric characters (country code $=\mathrm{ES} ; 12$ serial digits, the last 5 printed with a height of $8 \mathrm{~mm}$ ) according to the Spanish legislation (Real Decreto $947 / 2005$ updated by RD 1486/2009; Ministerio de Agricultura, Pesca y Alimentacion, 2005, 2009). For the M milk-recording system, groups of 12 ewes were $\mathrm{v}$-ID by reading individually the last 5 digits of the v-ET after being head-locked in the milking platform, and data were recorded on paper forms. Ear tags were cleaned at the start of the experiment and read by the milk recording operator from in front of the animal. Time necessary for v-ID of each 12 ewes was recorded by using an electronic chronometer (Geonaute Trt'L 100, Decathlon, Alcobendas, Spain). Milking time, including individual recording of milk yield without milk sampling, and observations (e.g., mastitis, cluster fall down) were recorded for each ewe group using the same chronometer and paper forms. Finally, milk recording data were manually transferred to an Excel (Microsoft Office 2003, Microsoft Corporation, Redmond, WA) spreadsheet on a desktop computer. Transfer time was recorded per group of 24 ewes.

$\boldsymbol{P D A}$. The $\mathrm{M}$ system was transformed in an SA milk-recording system by typing the v-ET codes and the milk volume data into a PDA (Pocket PC iPAQ h2200, Hewlett-Packard, Palo Alto, CA) provided with an adapted Excel spreadsheet version. Ewes were v-ID after being head-locked in the milking platform, as for $\mathrm{M}$, and data were recorded on the PDA keypad instead of on a paper form. No differences were detected for $\mathrm{M}$ and keypad typing, and the same time as for the M system was considered for v-ID and milk recording by group of 24-ewes in this case. Transfer of the PDArecorded data to a computer was done by Bluetooth connection using the appropriate software (Microsoft ActiveSynch 3.7, Microsoft Corporation); the spreadsheet files were automatically uploaded and stored in a previously assigned folder. Transfer time was also recorded for groups of 24 ewes.
$\boldsymbol{H H R}$. This SA system was based on using e-ID by high-density ceramic rumen boluses (e-RB) of small size (20 g; $11 \times 56$ mm, Rumitag, Esplugues de Llobregat, Barcelona, Spain), according to the Spanish legislation (RD 947/2005 updated with RD 1486/2009; Ministerio de Agricultura, Pesca y Alimentacion, 2005, 2009). Each e-RB contained a half-duplex glass-encapsulated radio frequency transponder $(32 \times 3.8 \mathrm{~mm})$ recorded with a serial number of 22 digits (animal bit, 1 translated as A; retagging counter, 0; user information-specie, 04; additional information, 000; country code, 724; national identification code, 12 serial digits) in agreement with the International Organization for Standardization 11784 and 11785 standards (ISO, 1996a,b).

The e-RB were read using an HHR transceiver with internal memory and keyboard (Smart Reader, Rumitag) connected to a 70-cm-long stick antenna (Sas-ISO, Rumitag). Bolus e-ID was automatically captured by placing the HHR stick antenna in the left flank from the rear of the ewe, by the operator in the milking parlor pit, at the end of milking of each animal and according to the procedure previously described in goats by AitSaidi et al. (2008). Milk yield data and observations of each animal were typed by the same operator on the transceiver keyboard. Milk recording time for groups of 12 ewes, including times needed for identification and milk volume and observations recording, was also measured by using the previously indicated chronometer. Data were stored in the memory of the HHR and automatically transferred to a desktop computer in the form of text file data by using the Bluetooth connection and the appropriate software provided by the manufacturer (Smart software v.3.3.2, Rumitag). Data text files were uploaded into spreadsheet files. Transfer time was also recorded for groups of 24 ewes.

Dynamic Reading of Dairy Ewes. Time of entrance into the milking parlor was measured for a total of 500 passages of dairy ewes, in groups of 12 , done on different test days. Entrance time was the time elapsed from passing in front of a frame antenna $(94 \times 52 \mathrm{~cm})$, placed on the left side of a raceway (width $=0.5 \mathrm{~m}$ ) and at $10 \mathrm{~m}$ from the milking parlor entrance, and restraining all ewes in the head lockers of the milking stalls. Dynamic reading of the e-RB was performed using an F-110 stationary transceiver (Rumitag) connected to the frame antenna and interfaced with a desk computer via RS232 connection. The F-110 unit automatically and simultaneously collected the e-RB number and time at which each ewe passed in front of the antenna by using commercial software (Gesmanga v2.6.2, Rumitag).

Dynamic reading efficiency (DRE) was calculated according to Caja et al. (1999a; 2014) and Conill et al. (2002), using the expression 
DRE $(\%)=[$ (number of read transponders $) /$

(number of readable transponders)] $\times 100$.

Total time and number of ewes were also used to calculate the speed of passage through the raceway.

\section{Experiment 2: Data Recording at Lambing}

To complete the flock-book of the farm, a total of 73 dairy (Manchega, $\mathrm{n}=31$; Lacaune, $\mathrm{n}=42$ ) and 80 meat (Ripollesa breed) ewes were used to register performance data at lambing. Data recording was done in groups of 7 to 10 ewes lambing as close as possible. Lambing occurred in different seasons - winter for dairy ewes and autumn of the next year for meat ewes - according to their respective reproduction schedule.

Before data recording at lambing, newborn lambs were weighed, their umbilical cord was cut and disinfected ( $2 \%$ iodine solution in ethanol 96\%), and they were tagged on the left ear with a small plastic ear tag (2-piece rigid plastic rectangular flaps; $1.5 \mathrm{~g} ; 1.0 \times 3.5$ cm; Tip-Tag, Azasa-Allflex) recorded with a correlative 3 -digit number and considered as official temporary ID until slaughtering or permanent ID for ewes intended for breeding.

Data recording at lambing was sequentially done by ewe group using $\mathrm{M}$ and SA recording systems. Ewes wore official v-ET similar to those described in experiment 1 recorded by the manufacturer. Ear tags unreadable by dirtiness were cleaned with warm water during data recording. Additionally, all ewes carried an e-RB recorded with the same code as the ear tags (as described in experiment 1). Ewes were restrained in head-lockers for lambing data recording and lamb data was provided by 1 assistant.

In the $\mathrm{M}$ system, lambing data was recorded on a paper form, and consisted of v-ID ( 5 digits of the last line of the official ear tag) of the ewe, date and type of lambing (single, twin or multiple lambs), lamb ear tag numbers, and individual data (sex, birth weight, and observations). Data from paper forms were manually uploaded to a database by typing on a computer keyboard. Recording and data uploading time were measured using an electronic chronometer (Geonaute Trt'L 100, Decathlon).

Lambing data recording by the SA system was done after the $\mathrm{M}$ recording procedure. In the SA system, ewe's e-ID was read by the HHR transceiver (Smart reader, Rumitag) with a stick antenna (SAS-ISO, Rumitag) and previously uploaded with the v-ET numbers of the ewes via Bluetooth connection and manufacturer software (Smart software v.3.3.2, Rumitag). Ewes were recorded in the same order as in the $\mathrm{M}$ system and lambing data was typed on the keyboard of the HHR reader. Lambing data saved in the memory of the HHR reader were automatically transferred to a computer via Bluetooth connection using the same software as previously discussed. Use of a PDA with v-ID, similar to that described in experiment 1 for data recording and downloading to a computer, was also considered.

\section{Experiment 3: BW Recording of Adult Ewes}

BW Recording. A total of 114 dairy (Manchega, n $=56$; Lacaune, $\mathrm{n}=58$ ) and 102 Ripollesa meat ewes were used to compare $\mathrm{BW}$ recording by $\mathrm{M}$ and $\mathrm{AU}$ systems with regard to labor time and data transfer efficiency. To obtain objective comparisons by sheep type, ewes were divided into groups of 20 according to breed and recorded on 12 test days for obtaining 480 BW data. In both systems, weighing was performed by 1 operator and 1 assistant previously trained and using the same electronic scale (Tru-Test SR2000, Pakuranga, Auckland, New Zealand) interfaced to an F-210 stationary reading unit (Rumitag) and to a desk computer via RS232 interface.

For the M weighing system, ewe group used the same raceway and scale, but it was necessary to restrain their head for reading the 5 digits of the v-ET. A paper form previously prepared was used to record the BW displayed for each ewe on the scale screen. Finally, BW data were manually uploaded to a database using the computer keyboard.

In the case of AU weighing recording, ewe's e-ID was automatically read by the F-210 unit and saved jointly with the BW in the memory of the scale. Both e-ID and BW were thereafter sent to the computer database by using specific software (PesoyTir version 1.0, Gesimpex Com., Barcelona, Spain). The same chronometer was used to measure times of ewe identification, BW recording, and to upload data onto a computer in $\mathrm{M}$ and AU systems. Use of the PDA, as previously indicated for lambing recording, was also done.

\section{Statistical Analyses}

Data were analyzed by ANOVA using the PROC GLM (version 9.2; SAS Institute Inc., Cary, NC). The statistical model for milk recording time contained the effects of the milking frequency $(\times 1$ or $\times 2)$, the recording system (M, PDA, or HHR), the test day order (d 1 to 10), the first-order interactions, and the residual error. Milk yield of each ewe at the test day was used as covariate. Time measurements were converted to a decimal scale ( $60 \mathrm{~s}=100$ units) for calculations. Comparison of times for milk recording data transfer was 
analyzed for groups of 24 ewes performed on the same test day.

The model used for lambing data recording time contained the effects of the system ( $\mathrm{M}$ or $\mathrm{SA}$ ), group of ewes (1 to 8), lambing season (winter or autumn of the following year), first-order interactions, and the residual error. For BW recording time, the model contained the effects of the BW recording system ( $\mathrm{M}$ or $\mathrm{AU}$ ), the test day (d 1 to 6 ), ewe type (dairy or meat), first-order interactions, and the residual error.

When the probability of one factor or the interaction term was not significant $(P>0.20)$, it was deleted from the model. Differences between least squares means (LSM) were separated using the PDIFF test in SAS and declared significant at $P<0.05$, unless otherwise indicated. Pearson correlation coefficients were also calculated.

\section{RESULTS AND DISCUSSION}

\section{Milk Recording Performances}

Milk Yield. Daily milk yield per ewe depended on milking frequency, ranging between 0.25 and $3.50 \mathrm{~L} / \mathrm{d}$ for $\times 2(1.40 \pm 0.08 \mathrm{~L} / \mathrm{d}$, on average $)$, and between 0.20 and $3.00 \mathrm{~L} / \mathrm{d}$ for $\times 1(0.98 \pm 0.05 \mathrm{~L} / \mathrm{d}$, on average $)$. The $\times 1$ ewes yielded $36 \%$ less milk daily than $\times 2$ ewes $(P$ $<0.001$ ), but the difference declined as lactation advanced (Figure 1). Milk loss produced as a consequence of $\times 1$ was in the range of values reported by Castillo et al. (2005) in Manchega (-37\%) and Lacaune (-13\%) dairy ewes at early lactation. Moreover, agreeing with the milking intervals applied (16- and 8-h) and previous studies in the same dairy ewes and conditions (Castillo et al., 2008), morning to evening milk yield ratio was 60:40, on average. As shown in Figure 1, milking frequency affected the rate of decrease of daily milk yield during the experimental period $(\times 2=14 \pm 1 \mathrm{~mL} / \mathrm{d} ; \times 1$ $=6 \pm 2 \mathrm{~mL} / \mathrm{d} ; P<0.001)$ with persistency coefficients for the whole period of 77.6 and $84.5 \%$, respectively.

Milk Recording Time. Milk recording time by 24 ewes (including ewe ID, machine milking, and stripping) by milk recording system is shown in Table 1 . According to the experimental procedure, the same values were considered for the $\mathrm{M}$ and PDA systems. Throughout the experimental period, milk recording time decreased with stage of lactation by $0.002 \mathrm{~min} / \mathrm{d}$ $\left(\mathrm{R}^{2}=0.40 ; P<0.001\right)$ for $\mathrm{M}$ and PDA and by 0.003 $\mathrm{min} / \mathrm{d}\left(\mathrm{R}^{2}=0.45 ; P<0.001\right)$ for the HHR system (Figure 2). Reduction in milk recording time in $\mathrm{M}$ and both SA systems throughout the experiment may be explained by the decreasing milk yield and increasing of operator skill as lactation advanced. Significant correlation $\left(\mathrm{R}^{2}=0.71 ; P<0.01\right)$ was found between milk recording time and milk yield in the $\mathrm{M}$ and $\mathrm{HHR}$ systems. Although scarce data exist on milk recording in small ruminants, the milk recording time values obtained in our results for $\mathrm{M}$ and HHR in the $\times 1$ ewes were lower than those previously reported by Ait-Saidi et al. (2008) in dairy goats milked $\times 1$. This was a consequence of the lower milk yield $(0.98 \pm 0.05 \mathrm{~L} / \mathrm{d})$ and the greater milk flow rate $(1.83 \pm 0.07 \mathrm{~L} / \mathrm{min})$ of our dairy ewes compared with the Ait-Saidi et al. (2008; $1.93 \mathrm{~L} / \mathrm{d}$ and $1.46 \mathrm{~L} / \mathrm{min})$ dairy goats. Moreover, no differences $(P=0.198)$ between milk recording time for the M, PDA, and HHR systems were observed throughout the experiment, which evolved similarly (Figure 2), indicating that the operator had enough expertise in SA milk recording at the start of the experiment.

For all recording systems (Table 1 ), milk recording time for $\times 2$ morning and $\times 1$ tended to differ $(P=$ $0.051)$, and $\times 2$ afternoon was greater than morning $(P$ $<0.001)$. According to milk yield and milk recording time, $\times 1$ represented approximately half the time taken daily in $\times 2$. Milking throughput ranged approximately between 122 to 150 ewes/h (9.6 to $11.8 \mathrm{~min} /$ group of 24 ewes), which agreed with the expected milking throughput for a double parallel (type Casse $2 \times 12$ ) milking platform in dairy sheep (Berger et al., 2004).

Milk Recording Data Transfer. On average, time for data transfer in the $M$ system $(3.3 \pm 0.1 \mathrm{~min} / 24$ ewes) from paper forms to the computer's database was longer than for the SA systems (Table $1 ; P<0.05$ ), regardless of the milking frequency used, agreeing with Ait-Saidi et al. (2008). Moreover, time for data transfer using the PDA system was faster than with HHR (0.3 \pm 0.1 vs. $0.8 \pm 0.1 \mathrm{~min} / 24$ ewes; $P<0.001$ ); this was a result of the automated and user-friendly procedure

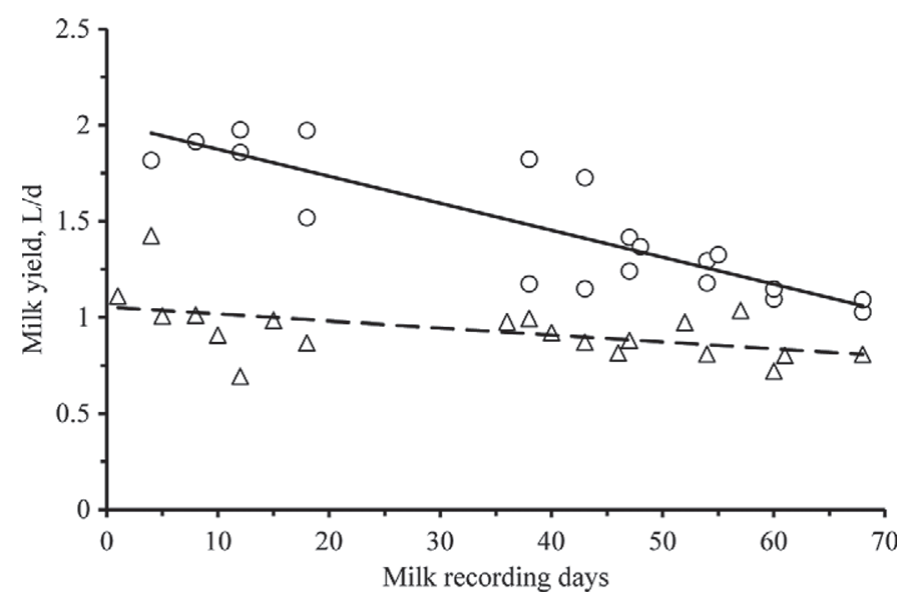

Figure 1. Change in daily milk yield according to elapsed time and milking frequency $(\times 1=\Delta ; \times 2=0)$ in dairy sheep. Regressions were $\mathrm{y}=1.20-0.006 \mathrm{x}\left(\mathrm{R}^{2}=0.45 ; P<0.01\right)$ for $\times 1$, and $\mathrm{y}=1.95-0.014 \mathrm{x}$ $\left(\mathrm{R}^{2}=0.92 ; P<0.001\right)$ for $\times 2$. 


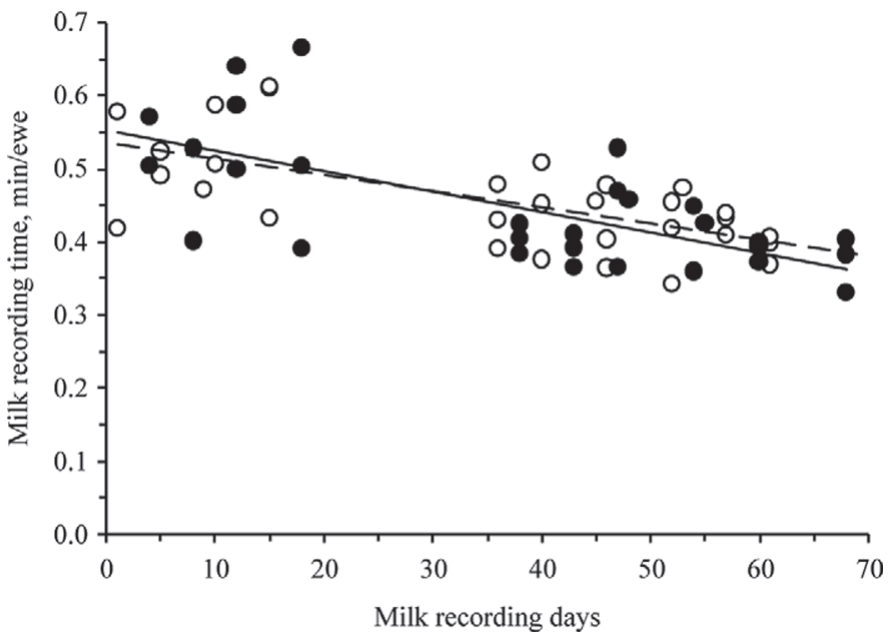

Figure 2. Change in milk recording time for manual (manual and personal digital assistant $=0$ ) or semiautomatic (handheld reader $=$ -) milk-recording systems in dairy ewes during the experiment. The regression for the manual and personal digital assistant system $(---)$ was $\mathrm{y}=0.54-0.002 \mathrm{x}\left(\mathrm{R}^{2}=0.40, P<0.001\right)$, and for the handheld reader system $(-)$ was $\mathrm{y}=0.55-0.003 \mathrm{x}\left(\mathrm{R}^{2}=0.45, P<0.001\right)$.

implemented for data transfer in the PDA used. The average time reduction of using HHR instead of $\mathrm{M}$ was $2.5 \mathrm{~min} / 24$ ewes $(76.1 \%$ ), which was lower than the previously estimated reduction values in goats under commercial farm (Caja et al., 1999b; $7.3 \mathrm{~min} / 24$ goats) and experimental farm conditions (Ait-Saidi et al., 2008; 3.7 $\min / 24$ goats). Moreover, the automatic data transfer avoided the possible mistakes of data typing and, in the case of both SA systems, time of data transfer was the fastest and not proportional to the amount of data.

Overall milk recording time was greater $(P<0.001)$ in $\mathrm{M}$ than in PDA, but no differences were detected between the PDA and HHR systems $(P=0.123)$ for both milking frequencies (Table 1 ). Total time savings between $\mathrm{M}$ and HHR treatments was on average $4.2 \pm$ $0.4 \mathrm{~min} / 24$ ewes ( $0.18 \mathrm{~min} /$ ewe) and varied according to milking frequency $(\times 1=2.8 \pm 0.4 \mathrm{~min} / 24$ ewes; $\times 2$ $=5.6 \pm 0.6 \mathrm{~min} / 24$ ewes; $P<0.001$ ). Likewise, overall time difference between $\mathrm{M}$ and PDA systems was 4.4 $\pm 0.4 \mathrm{~min} / 24$ ewes $(0.18 \mathrm{~min} /$ ewe $)$, on average, and also varied according to milking frequency $(\times 1=2.8$ $\pm 0.1 \mathrm{~min} / 24$ ewes; $\times 2=6.0 \pm 0.2 \mathrm{~min} / 24$ ewes; $P$ $<0.001)$. Differences between systems would increase with flock size for multiple groups of 24 ewes according to the milking parlor design used (2 milking platforms of 12 ewes) up to an approximate functional size of 400 ewes (72 min, on average, equivalent to $1 \mathrm{~h}$ and 12 $\min )$. Moreover, the $\times 1$ and $\times 2$ values may be related to the standard milk-recording methods recommended by ICAR (2012) in dairy sheep (A4 = official morning and afternoon recording method done monthly; $\mathrm{AT}=$ 
alternate method done at morning or afternoon milkings alternatively each month).

Errors reported during $\mathrm{M}$ milk recording (i.e., mistranscribed digits) were 1.2 and $0.8 \%$ for $\times 1$ and $\times 2$, respectively. Additionally, $1.7 \%$ more errors were found during data transfer, 2.9 and $2.5 \%$ in total for $\times 1$ and $\times 2$, respectively. No errors were detected for milk recording (actual milk yield data no available a posteriori) and no errors were produced during the automatic data transfer with HHR and PDA systems during the experiment. Error values in our data were greater than those reported by Ait-Saidi et al. (2008) when using M in dairy goats $(0.6 \%)$, which may be a consequence of the larger v-ID codes printed in the ear tags and of the smaller number of animals than in our study.

Dynamic Reading of Dairy Ewes. Time of entrance into the milking parlor per group of 12 ewes (1 platform) averaged $0.50 \pm 0.03 \mathrm{~min}$. Dynamic reading efficiency of all dairy ewes at the entrance to the milking parlor was $100 \%$. This value was similar to those reported earlier for dynamic reading of 32-mm half-duplex transponders either in injectable transponders or standard electronic boluses in calves, sheep, and goats (Caja et al., 1999a; Conill et al., 2002; Ghirardi et al., 2006), and allowed the utilization of small boluses for dynamic recording practices. Estimated passage speed of the ewes in our study was 1 ewe/s on average, which agreed with Ghirardi et al. (2006).

\section{Data Recording at Lambing}

On average, time of data recording at lambing was $24 \%$ greater $(P<0.05)$ in the dairy ewes lambing in winter than the meat ewes lambing in autumn, but the difference was more marked for M (30\%) than for SA $(15 \%)$ system, as shown in Table 2 . An interaction $(P$ $<0.01$ ) between data-recording system and season was found, which was a consequence of the improvement of operator skill throughout the experiment and of v-ET cleaning at the start of readings. Approximately, 5 of $10 \mathrm{v}$-ET in dairy ewes needed to be cleaned for the first visual reading. Time for cleaning was $0.2 \pm 0.01 \mathrm{~min} /$ ear tag, which accounted for $33 \%$ of the difference in total recording time between $\mathrm{M}$ and SA. On the contrary, in the meat ewes the operator had greater expertise in the procedures and the $\mathrm{v}$-ET had been already cleaned before starting the experiment. Despite the lambing period and ear tag cleaning, time employed for data recording at lambing was $10 \%$ greater in the $\mathrm{M}$ than $\mathrm{SA}$ system $(P<0.001)$.

With regard to lambing data transfer to a computer, values for the $\mathrm{M}$ system in the dairy ewes were $7 \%$ greater than in the meat ewes $(P<0.05)$ as a consequence of the operator expertise, but no difference between seasons was detected with the SA system ( $P$ $>0.05)$. In both periods, transfer time was faster for SA than for $\mathrm{M}(P<0.001), 0.06 \pm 0.01 \mathrm{~min} /$ ewe on average. Transfer time for $\mathrm{M}$ was related to the number of ewes, but this was not the case for SA. Time reduction by using SA, when compared with $\mathrm{M}$, was $4.87 \pm 0.17$ and $4.70 \pm 0.11 \mathrm{~min} / 10$ ewes $(0.49$ \pm 0.02 and $0.47 \pm 0.01 \mathrm{~min} /$ ewe) in dairy and meat ewes, respectively.

Overall time for data recording at lambing was also greater in $\mathrm{M}$ than in $\mathrm{SA}$, the difference being greater in winter than autumn $(7.96 \pm 0.23$ vs. $5.67 \pm 0.39$

Table 2. Comparison of manual and semiautomatic systems for data recording at lambing according to ewe type (values are least squares means)

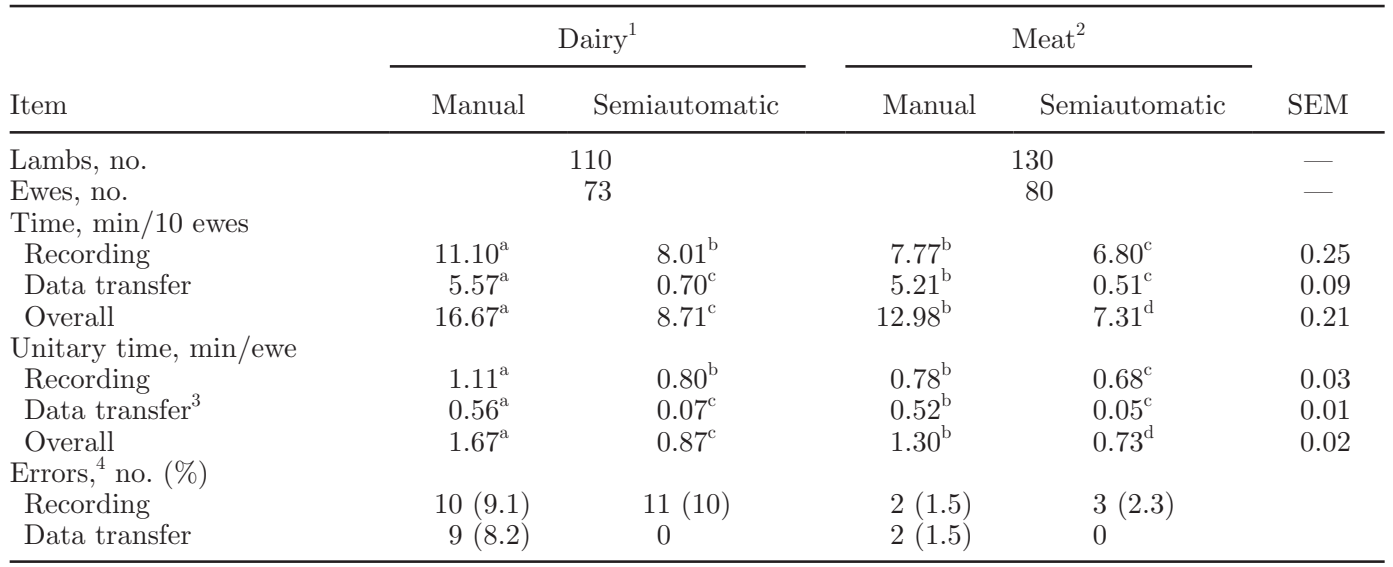

${ }^{\mathrm{a}-\mathrm{d}}$ Means with different superscripts within a row differ $(P<0.05)$.

${ }^{1}$ Lambing recording of dairy ewes during winter with a few experienced operator and dirty ear tags.

${ }^{2}$ Lambing recording of meat ewes with experienced operator and cleaned ear tags.

${ }^{3}$ From paper forms or intelligent transceiver to computer database.

${ }^{4}$ Errors were calculated according to the number of lambs. 
Table 3. Comparison of manual and automatic weighing systems in dairy and meat sheep (values are least squares means)

\begin{tabular}{|c|c|c|c|c|c|}
\hline \multirow[b]{2}{*}{ Item } & \multicolumn{2}{|c|}{ Dairy } & \multicolumn{2}{|c|}{ Meat } & \multirow[b]{2}{*}{ SEM } \\
\hline & Manual & Automatic & Manual & Automatic & \\
\hline Records, no. & 120 & 120 & 120 & 120 & - \\
\hline Mean BW, kg & $76.32^{\mathrm{a}}$ & $75.86^{\mathrm{a}}$ & $50.82^{\mathrm{b}}$ & $50.96^{\mathrm{b}}$ & 0.70 \\
\hline \multicolumn{6}{|c|}{ Time, $\min / 20$ ewes } \\
\hline Recording & $8.52^{\mathrm{b}}$ & $4.17^{\mathrm{d}}$ & $9.15^{\mathrm{a}}$ & $5.09^{\mathrm{c}}$ & 0.18 \\
\hline Data transfer ${ }^{1}$ & $3.58^{\mathrm{a}}$ & $0.35^{\mathrm{b}}$ & $3.64^{\mathrm{a}}$ & $0.33^{\mathrm{b}}$ & 0.07 \\
\hline Overall & $12.10^{\mathrm{b}}$ & $4.52^{\mathrm{d}}$ & $12.79^{\mathrm{a}}$ & $5.42^{\mathrm{c}}$ & 0.21 \\
\hline \multicolumn{6}{|c|}{ Unitary time, $\min /$ ewe } \\
\hline Recording & $0.43^{\mathrm{b}}$ & $0.21^{\mathrm{d}}$ & $0.46^{\mathrm{a}}$ & $0.25^{\mathrm{c}}$ & 0.01 \\
\hline Data transfer & $0.18^{\mathrm{a}}$ & $0.02^{\mathrm{b}}$ & $0.18^{\mathrm{a}}$ & $0.02^{\mathrm{b}}$ & 0.01 \\
\hline Overall & $0.61^{\mathrm{b}}$ & $0.23^{\mathrm{d}}$ & $0.64^{\mathrm{a}}$ & $0.27^{\mathrm{c}}$ & 0.01 \\
\hline \multicolumn{6}{|l|}{ Errors, no. (\%) } \\
\hline Identification & $3(2.5)$ & 0 & $3(2.5)$ & 0 & - \\
\hline Weight & $10(8.3)$ & 0 & $5(4.2)$ & 0 & - \\
\hline
\end{tabular}

${ }^{\mathrm{a}-\mathrm{d}}$ Means with different superscripts within a row differ $(P<0.05)$.

${ }^{1}$ From paper forms or stationary reader connected to automatic scale to computer database.

$\min / 10$ ewes, respectively; $P<0.001)$. These differences are expected to increase as flock size increases.

Errors registered for each recording system ( $\mathrm{M}$ or SA) are shown in Table 2. As expected, the number of errors in meat was lower than in dairy ewes due to the operator's greater expertise. No errors were detected for the data transfer by the SA system in either period. Advantages of using the SA system include feasibility, labor time saving, and accurate data transferred automatically and independently of the flock size.

\section{BW Recording of Adult Ewes}

Values of recorded BW ranged from 57.6 to $98.2 \mathrm{~kg}$ in dairy ewes and from 39.7 to $71.4 \mathrm{~kg}$ in meat ewes. Data of $\mathrm{M}$ and $\mathrm{AU}$ weight recording on the same test day correlated positively $\left(\mathrm{R}^{2}=0.97, P<0.001\right)$.

Weighing the meat ewes needed $11 \%$ more time $(P$ $<0.01)$ than the dairy ewes, regardless of the system used (Table 3). This difference was due to the tough behavior of the meat ewes, which had less direct contact with the shepherds and varied by test day $(P<$ $0.05)$. On average, BW recording time was $48 \%$ faster using AU than M $(P<0.001)$ for both sheep breeds (Table 3), agreeing with the results of Hua et al. (2012) when the automatic weighing system was implemented. Estimated weighing throughput by $\mathrm{AU}$ and $\mathrm{M}$ systems, were 262 and 136 ewes/h, respectively, which are in the ranges of previously reported data in other species by Turner and Smith (1975; 200 pigs/h), Filby et al. (1979; 80 calves/h), and Frappat (1996; 125 heifers/h).

Time required for transferring the $\mathrm{BW}$ data to a computer was $91 \%$ lower in AU than $\mathrm{M}(P<0.001)$, with no differences between sheep breed. Data transfer time in the M system depended on the number of ewes processed, but this was not the case for AU. A reduction of $3.27 \pm 0.08 \mathrm{~min} / 20$ ewes $(P<0.001)$ in the time needed for uploading BW records to the computer was observed in favor of AU (Table 3). Transfer time of $\mathrm{AU}$ for $\mathrm{BW}$ recording data $(0.34 \pm 0.03 \mathrm{~min} / 20$ ewes $)$ represented only 43 and $67 \%$ of the time necessary for data transfer using the SA system in milk recording of dairy ewes (Table 1) and in the case of lambing data (Table 2), respectively. Overall time of BW recording was $60 \%$ greater in $\mathrm{M}$ than $\mathrm{AU}(P<0.001)$ for both ewe breeds.

With regard to the errors occurred during BW recording, they were only detected for the $M$ system (Table 3) and included errors due to miscopied v-ID (2.5\%, on average) and BW data (6.3\%). No errors were detected during data transfer. Moreover, overall errors were numerically lower in meat ewes than in dairy ewes, although the difference was not significant $(P=0.18)$.

\section{CONCLUSIONS}

Regardless of the milk-recording system used ( $\mathrm{M}$ or SA), no difference in time devoted exclusively to milk recording was noted for our milking parlor and flock size conditions. Nevertheless, when data transfer was included, total milk recording time was markedly longer in the M system. On the contrary, when SA systems were used total milk recording time was faster than M and no errors were detected. We stressed the need for automated and user-friendly procedures (e.g., plug and play) for instantaneous milk recording data transfer in the dairy sheep industry. Despite the similar throughput of the PDA and the HHR systems, the latter was preferred due to the lower risk of mistakes in ewe iden- 
tification. Semiautomatic systems implemented in our study were time-effective for milk recording in dairy ewes, saving more than $1 \mathrm{~h}$ of labor time for a flock size of 400 ewes milked in a parallel $2 \times 12$-stall milking parlor. Use of e-ID for SA (lambing data recording) and $\mathrm{AU}$ (BW recording) performance recording in meat and dairy sheep farms saved approximately $50 \%$ of the time required and increased the reliability of the collected data (lower misrecorded data and no transmission errors). Further research will evaluate the costs of implementing $\mathrm{M}$ and SA systems for milk recording and other performances recording in sheep farms.

\section{ACKNOWLEDGMENTS}

This work is part of a Plan Nacional $\mathrm{I}+\mathrm{D}+\mathrm{i}$ research project (AGL-2007-64541) funded by the Spanish Ministry of Education (Madrid, Spain)."The authors are also grateful to Ramon Costa and the team of the Servei de Granges i Camps Experimentals, Universitat Autònoma de Barcelona, Bellaterra, Spain) for the care of the animals and to Nic Aldam (Barcelona, Spain) for the English revision of the manuscript.

\section{REFERENCES}

Abas, Z., A. L. Symeonidis, A. Batzios, Z. Basdagianni, G. Banos, P. A. Mitkas, E. Sinapis, and A. Pampoukidou. 2007. AMNOS-Mobile: Exploiting handheld computers in efficient sheep recording. Pages 65-68 in Breeding, Production Recording, Health and the Evaluation of Farm Animals. J. Kyntäjä, K. Lampinen, A. Rosati and C. Mosconi, ed. EAAP Publication No. 121. Wageningen Academic, Wageningen, the Netherlands.

ADAS. 2006. ADAS field trials in support of producing a regulatory impact assessment for sheep identification in England. Accessed Feb. 17, 2014. http://archive.defra.gov.uk/foodfarm/farmanimal/ movements/sheep/documents/adas-final-report.pdf.

Afimilk. 2014. AfiFree Milk Meters. Accessed Feb. 17, 2014. http:// www.afimilk.com/products/sheep-goats/afifree-milk-meters.

Ait-Saidi, A., G. Caja, S. Carné, A. A. K. Salama, and J. J. Ghirardi. 2008. Short communication: Comparison of manual versus semiautomatic milk recording systems in dairy goats. J. Dairy Sci. 91:1438-1442.

Bass, P. D., D. L. Pendell, D. L. Morris, J. A. Scanga, K. E. Belk, T. G. Field, J. N. Sofos, J. D. Tatum, and G. C. Smith. 2008. Review: Sheep traceability systems in selected countries outside of North America. Prof. Anim. Sci. 24:277-286.

Berger, Y., P. Billon, F. Bocquier, G. Caja, A. Cannas, B. Mckusick, P.-G. Marnet, and D. Thomas. 2004. General management of dairy ewes. Pages 93-108 in Principles of Sheep Dairying in North America. University of Wisconsin, Madison.

Butler, L. J., J. W. Oltjen, V. J. Velez, J. L. Evans, F. Haque, L. H. Bennett, and G. Caja. 2009. Cost-Benefit analysis of the U.S. National Animal Identification System (NAIS) in California. Page 488 in Book of Abstracts, 60th Annual Meeting EAAP, Barcelona, Spain. Wageningen Pers, Wageningen, the Netherlands.

Caja, G., F. Barillet, R. Nehring, C. Marie, O. Ribó, E. Ricard, G. Lagriffoul, C. Conill, M. R. Aurel, and M. Jacquin. 1996. Comparison of different devices for electronic identification in dairy sheep. Pages 349-353 in Performance Recording of Animals: State of the Art, 1996. J. Renaud and J. van Gelder, ed. EAAP Publication No. 87. Wageningen Pers, Wageningen, the Netherlands.
Caja, G., S. Carné, A. A. K. Salama, A. Ait-Saidi, M. A. RojasOlivares, M. Rovai, J. Capote, N. Castro, A. Argüello, M. Ayadi, R. Aljumaah, and M. A. Alshaikh. 2014. State-of-the-art electronic identification techniques and applications in goats. Small Rumin. Res. 121:42-50. http://dx.doi.org/10.1016/j. smallrumres.2014.05.012.

Caja, G., C. Conill, R. Nehring, and O. Ribó. 1999a. Development of a ceramic bolus for the permanent electronic identification of sheep, goat and cattle. Comp. Elec. Agric. 24:45-63.

Caja, G., J. J. Ghirardi, M. Hernandez-Jover, and D. Garín. 2004. Diversity of animal identification techniques: From fire age to electronic age. Pages 21-41 in Seminar on Development of Animal Identification and Recording Systems for Developing Countries. R. Pauw, S. Mack, and J. Mäki-Hokkonen, ed. ICAR Technical Series No. 9, Rome, Italy.

Caja, G., S. Peris, C. Conill, R. Nehring, R. Roca, O. Ribó, and M. J. Milán. 1999b. Implementation of a system based on electronic identification for the official milk recording of dairy goats in Catalonia. Pages 406-411 in Milking and Milk Production of Dairy Sheep and Goats. F. Barillet and N. P. Zervas, ed. EAAP Publication No. 95. Wageningen Pers, Wageningen, the Netherlands.

Caja, G., O. Ribó, and R. Nehring. 1998. Evaluation of migratory distance of passive transponders injected in different body sites of adult sheep for electronic identification. Livest. Prod. Sci. $55: 279-289$.

Cappai, M. G., M. Picciau, G. Nieddu, M. P. L. Bitti, and W. Pinna. 2014. Long term performance of RFID technology in the large scale identification of small ruminants through electronic ceramic boluses: Implications for animal welfare and regulation compliance. Small Rumin. Res. 117:169-175.

Castillo, V., X. Such, G. Caja, E. Albanell, and R. Casals. 2005. Mid-term lactational effects of once- versus twice-daily milking in Manchega and Lacaune dairy ewes. J. Dairy Sci. 88(Suppl. 1):286-287. (Abstr.)

Castillo, V., X. Such, G. Caja, R. Casals, E. Albanell, and A. A. K. Salama. 2008. Effect of milking interval on milk secretion and mammary tight junction permeability in dairy ewes. J. Dairy Sci. 91:2610-2619.

Conill, C., G. Caja, R. Nehring, and O. Ribó. 2002. The use of passive injectable transponders in fattening lambs from birth to slaughter: Effects of injection position age and breed. J. Anim. Sci. 80:919-925.

DeLaval. 2014. Milk meter DeLaval MM25 SG. Accessed Feb. 17, 2014. http://www.delaval.es/ImageVaultFiles/id_5066/cf_5/11799_ Medidor_MM25-SG.PDF.

European Commission. 2004. Council regulation (EC) No 21/2004 of 17 December 2003 establishing a system for the identification and registration of ovine and caprine animals and amending Regulation (EC) No 1782/2003 and Directives 92/102/EEC and 64/432/ EEC. European Commission, Brussels, Belgium.

European Commission. 2008. Commission regulation (EC) No 933/2008 of 23 September 2008 amending the Annex to Council Regulation (EC) No 21/2004 as regards the means of identification of animals and the content of the movement documents. European Commission, Brussels, Belgium.

European Commission. 2009. Commission regulation (EC) No 759/2009 of 19 August 2009 amending the Annex to Council Regulation (EC) No 21/2004 establishing a system for the identification and registration of ovine and caprine animals. European Commission, Brussels, Belgium.

Filby, D. E., M. J. B. Turner, and M. J. Street. 1979. A walk-through weigher for dairy cows. J. Agric. Eng. Res. 24:67-78.

Frappat, B. 1996. Automation of weighing operations with electronic ear tags. Pages 345-348 in Performance Recording of Animals: State of the art, 1996. J. Renaud and J. van Gelder, ed. EAAP Publication No. 87. Wageningen Pers, Wageningen, The Netherlands.

Garín, D., G. Caja, and C. Conill. 2003. Effects of small ruminal boluses used for electronic identification of lambs on the growth and development of the reticulorumen. J. Anim. Sci. 81:879-884. 
Ghirardi, J. J., G. Caja, D. Garín, M. Hernández-Jover, O. Ribó, and J. Casellas. 2006. Retention of different sizes of electronic identification boluses in the forestomachs of sheep. J. Anim. Sci. 84:2865-2872.

Grassi, P. 2013. Implementing a traceability system for the pig chain based on electronic ear tags and molecular markers. PhD Thesis. Univ. Autonoma of Barcelona, Bellaterra, Spain.

Hua, L., J. Zhou, Y. Yu, S. Yang, Q. Wang, and T. Zhou. 2012. Design and experiment of livestock auto weighing system. Trans. Chin. Soc. Agric. Eng. 28:15-20.

International Committee for Animal Recording (ICAR). 2012. International Agreement of Recording Practices. Guidelines approved by the General Assembly held in Cork, Ireland. ICAR, Rome, Italy.

International Committee for Animal Recording (ICAR). 2014. Dairy sheep milk inquiry. Accessed Feb. 17, 2014. http://www.surveyicar.org/sheep_survey4/.

International Organization for Standardization (ISO). 1996a. Agricultural Equipment. Radio-frequency identification of animals-Code structure. ISO 11784:1996 (E), 2nd ed. ISO, Geneva, Switzerland.

International Organization for Standardization (ISO). 1996b. Radio-frequency identification of animals-Technical concept. ISO 11785:1996 (E), 2nd ed. ISO, Geneva, Switzerland.

MAPA. 2007. Guías de prácticas correctas de higiene Ovino de leche. Accessed Feb.17, 2014. http://www.magrama.gob.es/es/ganaderia/ publicaciones/CCAE_tcm7-5979.pdf.

Marie, C., G. Caja, F. Barillet, O. Ribó, R. Nehring, and E. Ricard. 1994. Electronic identification in sheep: initial results and considerations for application and testing of transponders. Pages 197-202 in Milk and Beef Recording: State of the Art, 1994. L. Lajoie, and S. Lafontaine, ed. EAAP Publication No. 75. Wageningen Pers, Wageningen, the Netherlands.

Milán, M. J., F. Frendi, R. González-González, and G. Caja. 2014. Cost structure and profitability of Spanish Assaf dairy sheep farms in Spain. J. Dairy Sci. 97:5239-5249. http://dx.doi.org/10.3168/ jds.2013-7884.

Ministerio de Agricultura. Pesca y Alimentacion. 2005. Real Decreto $947 / 2005$, de 29 de julio, por el que se establece un sistema de identificación y registro de los animales de las especies ovina y caprina. MAGRAMA, Madrid, Spain.
Ministerio de Agricultura. Pesca y Alimentacion. 2009. Real Decreto $1486 / 2009$, de 26 de septiembre, por el que se modifica el Real Decreto $947 / 2005$, de 29 de julio, por el que se establece un sistema de identificación y registro de los animales de las especies ovina y caprina. MAGRAMA, Madrid, Spain.

Morris, J. E., G. M. Cronin, and R. D. Bush. 2012. Improving sheep production and welfare in extensive systems through precision sheep management. Anim. Prod. Sci. 52:665-670.

Ordolff, D. 2001. Introduction of electronics into milking technology. Comp. Elec. Agric. 30:125-149.

Ricard, E., J. Arhainx, J. P. Guillouet, F. Bouvier, M. Jacquin, P. Chastin, J. M. Astruc, G. Lagriffoul, E. Manfredi, and F. Barillet. 1994. On-farm test of INRA portable electronic jars for automatized milk recording of sheep and goats. Pages 47-51 in Performance Recording of Animals. P. Gailon and Y. Chabert, ed. EAAP Publication No. 50. Wageningen Pudoc, Wageningen, the Netherlands.

Saa, C., M. J. Milán, G. Caja, and J. J. Ghirardi. 2005. Cost evaluation of the use of conventional and electronic identification and registration systems for the national sheep and goat populations in Spain. J. Anim. Sci. 83:1215-1225.

Samad, A., P. Murdeshwar, and Z. Hameed. 2010. High-credibility RFID-based animal data recording system suitable for small-holding rural dairy farmers. Comp. Elec. Agric. 73:213-218.

San Miguel, O., G. Caja, R. Nehring, F. Miranda, J. A. Merino, V. Almansa, and M. J. Lueso. 2005. Results of the IDEA project on cattle, sheep and goats in Spain. Pages 357-359 in Performance Recording of Animals. State of the Art, 2004. M. Guellouz, A. Dimitriadou, and C. Mosconi, ed. EAAP Publication No. 113. Wageningen Academic Publishers, Wageningen, the Netherlands.

Turner, M. J. B., and R. A. Smith. 1975. Recent developments in the handling and weighing of farm animals. Livest. Prod. Sci. 2:289-295.

United Kingdom Parliament. 2008. Food Security, 30 Jun 2008: Column 656. Accessed Apr. 23, 2014. http://www.publications.parliament. uk/pa/cm200708/cmhansrd/cm080630/debtext/80630-0014.htm. 